\title{
EVALUATION OF BONE HEIGHT CHANGES IN THREE IMPLANTS RETAINED MANDIBULAR OVERDENTURE USING THREE DIFFERENT ATTACHMENT DESIGN. A RANDOMIZED CLINICAL TRIAL
}

\author{
Nouran Abdel Nabi* and Nourhan Ahmed Ragheb ${ }^{* *}$
}

\begin{abstract}
Introduction: The use of more than two implants for mandibular overdentures will improve the retention and stability. The aim of this randomized clinical trial was to compare bone height changes around three implant retained mandibular overdentures using ball, locator and telescopic attachment

Materials and Methods: Twenty-four completely edentulous patients were seeking to install three implants in the edentulous mandible to improve retention of their complete dentures. Three implants were installed in the canine-premolar areas bilaterally and one in the midline. Three month healing period was allowed, and then patients were randomized using sealed envelopes into three groups; patients receiving ball attachments, patients receiving locator attachments and patients receiving telescopic attachments. Bone height changes were recorded using standardized peri-apical x-rays at the day of pick up, at 3,6 and 12 months follow up. One Way ANOVA test was used followed by Tukey`s Post Hoc test for multiple comparisons. Two sided $p$ values less than 0.05 was considered statistically significant.
\end{abstract}

Results: At 6 and 12 month follow up the middle implant showed greater significant bone height changes than the right and left implants in all of the three groups. Ball attachment group showed a greater significant bone height changes when compared to the locator and telescopic attachment group at 6 and 12 month follow up.

Conclusion: The implant installed in the mid line showed the greatest significant bone height changes and the ball attachment have experienced the greatest significant bone height changes after 12 month follow up period.

KEY WORDS: Three implant retained overdenture, ball attachment, locator attachment, telescopic attachment, bone height changes.

* Assistant Professor, Prosthodontist, Department of Prosthodontics, Faculty of Oral \& Dental Medicine, Cairo University, Cairo, Egypt.

** Lecturer, Prosthodontist, Department of Prosthodontics, Faculty of Oral \& Dental Medicine, Kafr El-Shiekh University, Kafr El-Shiekh, Egypt. 


\section{INTRODUCTION}

An overdenture prosthesis is an alternative that results in more patient satisfaction, and retention when compared to conventional complete dentures. ${ }^{1,2}$ Furthermore, when compared with fixed implant-supported complete dentures, overdentures require less implants, resulting in decreased initial cost of the prosthesis ${ }^{3}$ Besides, overdentures facilitates proper oral hygiene measures, maintain healthy oral mucosa and peri-implant tissues, mostly in elderly patients with motor disabilities. ${ }^{4}$

To increase stability and retention of dentures, an additional attachment system can be used for cases of mandibular over denture. ${ }^{5}$ All present attachment systems are designed to prevent vertical movement of the denture and can be used as a solitary attachment attached directly to the implant or connected to a bar system. ${ }^{6}$ Implant retained overdenture attachments can be categorized into, bars, studs, magnets, and telescopic copings. ${ }^{7}$ The selection of the suitable kind of attachment will depend on many factors; anatomy of the alveolar ridge, high muscle attachment and definite patient related factors. ${ }^{8}$

Telescopic retainers consist of primary and secondary coping. Telescopic retainers would provide excellent retention resulting from the frictional fit between the primary and secondary coping. Furthermore, the circumferential relation among the outer and inner copings that have resulted in better force spreading with axial transfer of occlusal forces resulting in decreased torque to the underlying abutments.$^{9,10}$ Telescopic retainers would also provide better retentive and stabilizing properties with a splinting action ${ }^{9,10}$, they also offer excellent oral hygiene maintenance ${ }^{9}$ it has been reported that telescopic retainers used in overdentures have been given the name of "Perio - overdentures" due to their excellent convenience for cleaning thus preventing the incidence of hyperplasia and peri-implantitis.$^{11}$

On the other hand, the self-standing type of attachments, such as ball attachment, magnet attachment, and Locator have advantages of easing the oral hygiene maintenance and also its use in cases of narrow inter-arch space. ${ }^{12,13}$ Ball attachments are considered to be more simple, frequently used and properly proven attachment systems used for anchorage on both splinted and non-splinted implants ${ }^{14,15}$,offering high retentive ability, decreasing loading forces beside the implants, and help in management of non-paralleling implants. However, their clinical application require more vertical and buccolingual spaces, probably encroaching on the tongue space, mostly in tapered arches. Also, gingival hyperplasia throughout the attachment system may complicate the plaque control and the hygiene maintenance. ${ }^{16}$ Furthermore, Ball attachments were considered the simplest type of attachments for clinical application with tooth-or implant-supported overdentures. ${ }^{15}$

The locator attachment is designed to make insertion and removal simpler, has double retention, and ability to self-align therefore increasing its resiliency and tolerance for implant divergency up to $40^{\circ}$. Owing to these design characters, the locator quickly became one of the most popular stud attachments. This type of attachment is available in different colors with various retention values. ${ }^{18,19}$ Locator attachments existing in different vertical heights, locator attachments are considered to be resilient, retentive which have tolerance for implant divergency (up to $40^{\circ}$ ). ${ }^{15}$ Moreover, the repair and maintenance are easy and fast . ${ }^{6}$

Consistent to recent Cochrane Systematic Review, there is no sufficient evidence to determine the true efficiency of numerous attachment systems for mandibular overdentures, concerning patient's requirements and satisfaction, prosthodontic maintenance, and costs.$^{20}$ The number of implants required to provide a proper mandibular implant overdenture treatment outcome still debatable. It was stated that the worth of fewer implants as a cost saving method has a value for several patients. 
However, the use of more than two implants is recommended in specific cases to increase the overdenture stability and conserving the supporting peri-implant bone. ${ }^{21}$

The use of three or four implants provide an angular relationship between the implants as an alternate of a straight-line relationship. Moreover, in the three- implant-supported overdenture, the most anteriorly positioned implant may generate indirect retention for the denture by preventing the intrusion of the anterior part of the denture towards the tissues. ${ }^{22}$

The McGill and York ${ }^{23,24}$ had proposed that two implant overdenture should be the routine treatment protocol for edentulous mandible. On the other hand, Mericske-Stern et al ${ }^{8}$ reported that three or four implants are the most appropriate option for rehabilitation of edentulous mandible, mainly in patients with large or V-shaped anterior ridges, to assure proper bar designs and satisfactory overdentures.

One of the long term clinical evaluation of the implants used to support an overdenture is observing of the marginal bone level around the implants. Changes in marginal bone levels that are beyond the physiologic limits would result in loss of bone height around the anchoring implant. Bone loss of about $1.5 \mathrm{~mm}$ after the first year of loading with an additional $0.2 \mathrm{~mm}$ amount of bone loss per year is measured to be within the physiologic limits. 25-27 The evaluation of changes in bone height round the implants can be carried out by matching standardized peri-apical $\mathrm{x}$-rays at different intervals.

A marginal peri-implant bone loss of about $1 \mathrm{~mm}$ in the first year and of additional $0.1 \mathrm{~mm}$ yearly has been reported as normal in the literature. This incidence of bone loss can differ due to unfavorable conditions of masticatory loading and plaque accumulation on the implant sites, which could affect the prognosis of the oral rehabilitation treatment over the years since it is related to the preservation of the supporting tissues. ${ }^{28-31}$ Meijer et al. ${ }^{32}$ reported that the use of stud attachments as an alternate of splinted implants with bars to ensure a balanced distribution of stresses. Comparably, Menicucci et al ${ }^{33}$ reported that ball attachments distribute less stress to the implants than a bar/clip design.

The aim of this study was to compare the bone height changes around three implant telescopic, locator, and ball retained mandibular overdentures.

\section{MATERIALS AND METHODS}

Twenty-four completely edentulous patients were recruited from the outpatient clinic of Removable Prosthodontics Cairo University.

\section{Sample size calculation}

The sample size was calculated based on the work by Nouran Abdel Nabi 2017. ${ }^{34}$ An estimate based on expert opinion of 0.4 was used. The Independent-t-test was used, PS software. After 12 month follow up the mean bone height changes of $9.53 \pm 0.25 \mathrm{~mm}$ based on the work done by Nouran Abdel Nabi 2017. Alpha significance $=0.05$, and the $80 \%$ power of the study was used. The calculated sample size per group was 7 patients, and 15\% to compensate for drop outs, then 8 patients per group, so total number of patients was 24 patients. Ethical approval for the study was obtained from the Ethical Committee of Faculty of Dentistry Kafrelshiekh University of number KD/11/21. This trial was registered in clinical trial.gov with number of NCT04928274.

All patients recruited were seeking to install implants in their lower jaw, and have to meet the following inclusion criteria: age ranging from 50 to 70 years old, patients should have no contraindication for implant installation, all patients should perform a glycosylated hemoglobin analysis and only up to 8 were included in the study. All patients had to sign an informed consent before the start of 
the study, and have to comply with the assigned follow-ups. Patients with any contraindications for implant placement or those who didn't comply with the follow ups were excluded from the study. Males and females were included in this study, 17 males and 7 females.

All patients included had maxillary and mandibular complete dentures fabricated following the conventional steps, after a period of 6 weeks adaptation, all patients were ready for implant installation. The lower denture was duplicated into a radiographic stent, having radio-opaque markers in the areas of implant installation. All patients had a CBCT $x$ ray wearing the radiographic stent, to allow for proper implant planning and to visualize the height and width of the osteotomy site. The radiographic stent was then modified to a surgical stent by making a tunnel corresponding to the site of implant installation. All Patients in this study received three implants in the lower jaw at the premolar-canine area bilaterally and one implant in the midline at the central incisor area.

\section{Implant Installation}

At the day of surgery all patients were instructed to take $2 \mathrm{gm}$ of amoxicillin 2 hours before surgery. All implants used in this study was Implant Direct*, of width $3.7 \mathrm{~mm}$ and length $11.5 \mathrm{~mm}$, drilling was carried out following the implant manufacturer instructions. Suturing was then carried out, and the patient denture was modified using a soft liner at the day of surgery, patients were recalled after 7 days for suture removal.

A delayed (conventional) loading protocol was followed in this study and all patients were recalled after 3 month from implant installation for a second stage surgery, healing abutments were screwed and left for ten days for proper healing. Patients were then randomized using sealed envelopes into three groups each group having 8 patients;

First group: Patients receiving 3 ball attachments

Second group: Patients receiving 3 locator attachments

Third group: Patients receiving 3 telescopic attachments.

The first group consisted of 4 males and 4 females, while in the second group consisted of 6 males and 2 females, and in the third group consisted of 7 males and 1 female.

\section{First and second group of patient}

Both attachments; Ball attachment** and locator attachment ${ }^{* * *}$ were screwed to the implants with a torque of $30 \mathrm{~N}$ (Fig.1, 2), and the corresponding nylon cap matrix and the white retentive cap offering standard retention for locator attachment , both matrixes were placed on top of the attachments. The mandibular denture was then modified by cutting a small hole in the area corresponding to the attachment, a red die was placed on the fitting surface of the modified denture to ensure that there was no interference between the acrylic resin and the attachment matrix. The mandibular denture was checked for proper seating, and the occlusion with the maxillary denture was properly checked.

A small piece of rubber dam was used to block the undercuts present in both attachments. The denture was then properly seated in place then a soft mix of self-cure acrylic resin was then added to the hole of the modified denture, the patient was then asked to bite gently in centric relation.

\footnotetext{
* Screw implant, screw plant implant. Implant direct TM LLC Spectra-system Dental Implants, 27030 Malibu Hills, USA.

** Ball attachment Implant direct, TM LLC Spectra-system Dental Implants, 27030 Malibu Hills, USA.

*** Screw plant Locator Implant direct, TM LLC Spectra-system Dental Implants, 27030 Malibu Hills, USA.
} 


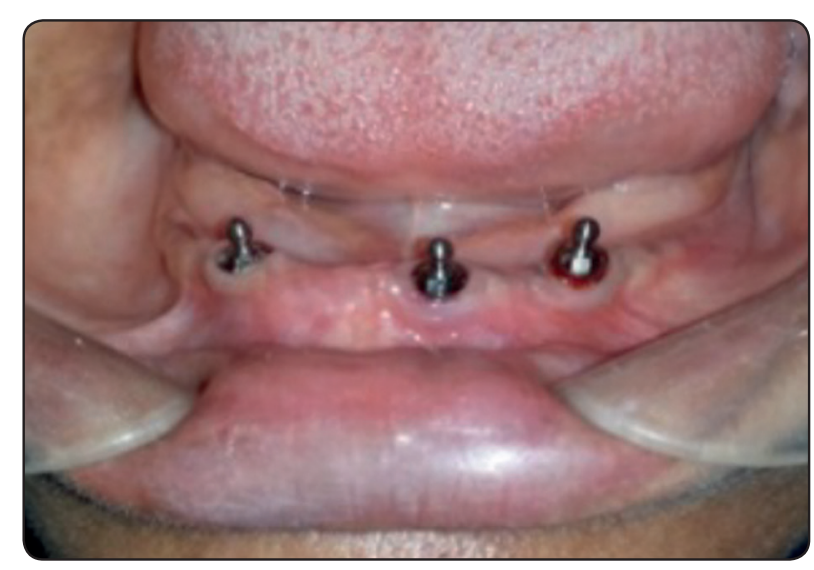

Fig. (1): Three ball attachments

After complete setting of acrylic resin the denture was removed and pick up of the matrix was checked. All excess acrylic resin was removed and then polished. Patients were recalled 3 days after pick up to check if there are any premature contacts or areas that required relief. This procedure was carried out for both attachments used in this study.

\section{Third group of patients}

After proper healing, a lower primary impression was made using alginate impression material, and a stone cast was poured identifying the areas of the healing abutments. Corresponding to the areas of healing abutments, three layers of pink wax was placed over each healing abutment to simulate the height of the transfer coping. A special tray was then fabricated having an increased height anteriorly (height of the pink wax) to accommodate for the transfer copings during impression making. The healing abutment was removed and a transfer coping was screwed to all implants in both groups of patients. A closed tray impression was made for all patients, using a medium impression material ${ }^{*}$, and then the implant analogue was screwed to each transfer coping and the tissue mimic material was injected around each implant and the cast was

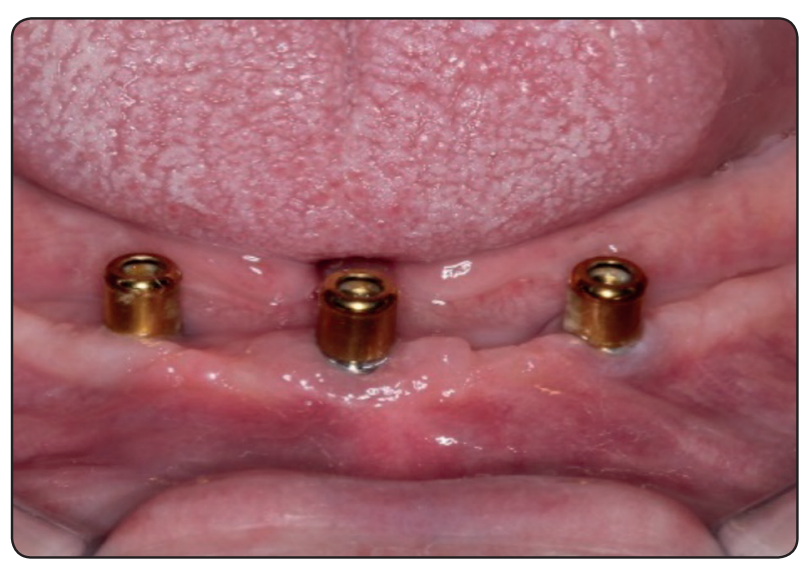

Fig. (2) Three locator attachments

poured into an extra hard stone cast.

The transfer copings were then removed and the abutments were screwed to each implant. All abutments were being milled to be parallel to each other using a milling machine. Over each abutment a secondary coping was fabricated by wax build-up having the same shape of each abutment, and then this wax built up was casted into chrome-cobalt. The primary coping in this study was considered to be the abutment, and the secondary coping was made of chrome-cobalt. The abutments were then screwed in the patient's mouth (Fig 3 a), and the secondary coping was checked for proper seating and placed on top of the abutment. The patient's denture was modified by drilling three holes corresponding to the site of the abutment with the secondary copings. A soft mix of self-cure acrylic resin placed through the three corresponding holes and the patient was asked to bite in centric relation. After setting of the self-cure acrylic resin, the three chrome-cobalt secondary copings were embedded in the fitting surface of the denture (Fig 3 b). The lower denture was polished, and then the patient was recalled after 3 days to check for any pressure areas or any adjustment in occlusion.

\footnotetext{
* ImpregumTM ,PentaTM , 3M ESPE, Poly ether impression material, Seefeld, Germany.
} 
Bone height measurement for all three groups of patients

At the day of prosthesis delivery (day of pick up) standardized peri-apical $\mathrm{x}$-rays were recorded for the three groups of patients and then at the following intervals; at the day of pick up (baseline), at 3 month follow up, at 6 month follow up and then 12 month follow up. Standardized Peri-apical $\mathrm{x}$ rays were carried out using the parallel technique, by using the bite block of the Rinn XCP set*. Rinn XCP set consists of a bite block (film holder) and an extra-oral collimator ring that is parallel to the film holding plane of the $\mathrm{x}$-ray film holder. The

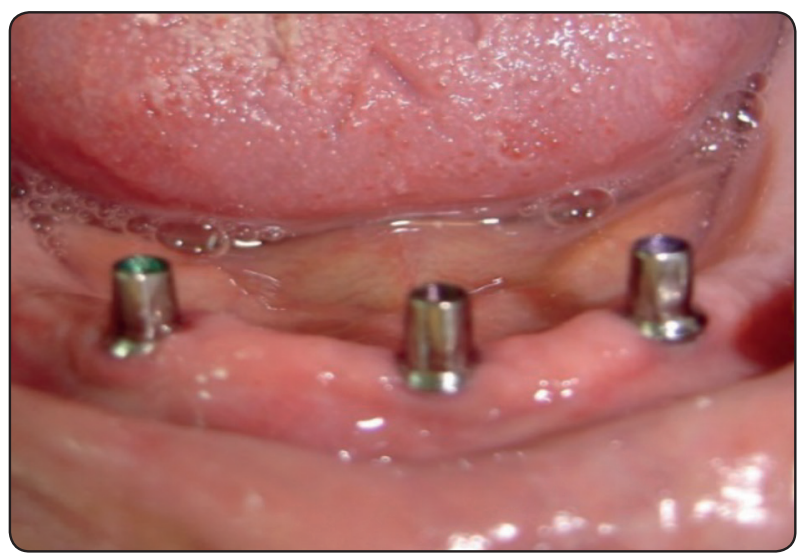

Fig. (3) a: Three telescopic attachments

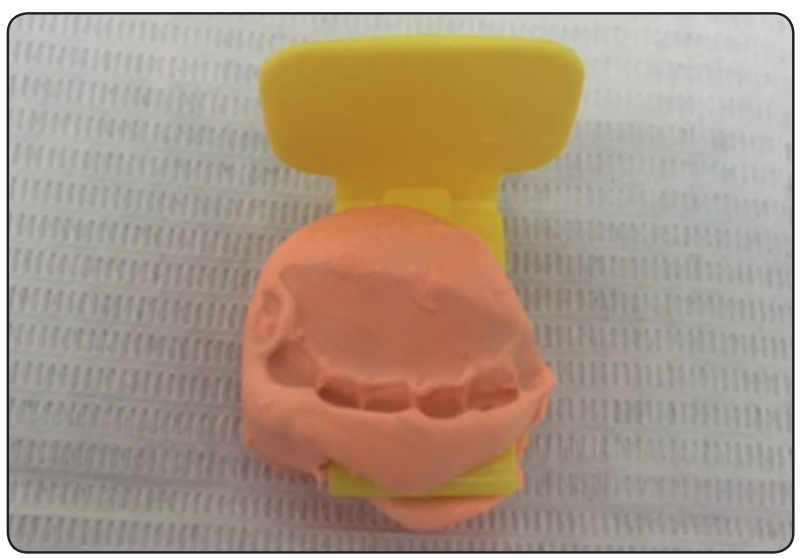

Fig (4a): bite block of the patient bite block is used to hold the sensor (film), and the extra-oral collimator ring is used to direct the cone. Addition silicon impression material ${ }^{* *}$ was placed on the top and bottom of the bite block (Fig 4a), and the patient was asked to bite on the bite block resulting in an index that was securely attached to the bite block (Fig 4b). Each patient has his own bite block which was saved in his file.

The Digora software ${ }^{* * *}$ was then used to measure bone height changes on the mesial and distal surface of each implant. The Digora software was then used to measure bone height changes on the mesial and distal surface of each implant. The implant in the

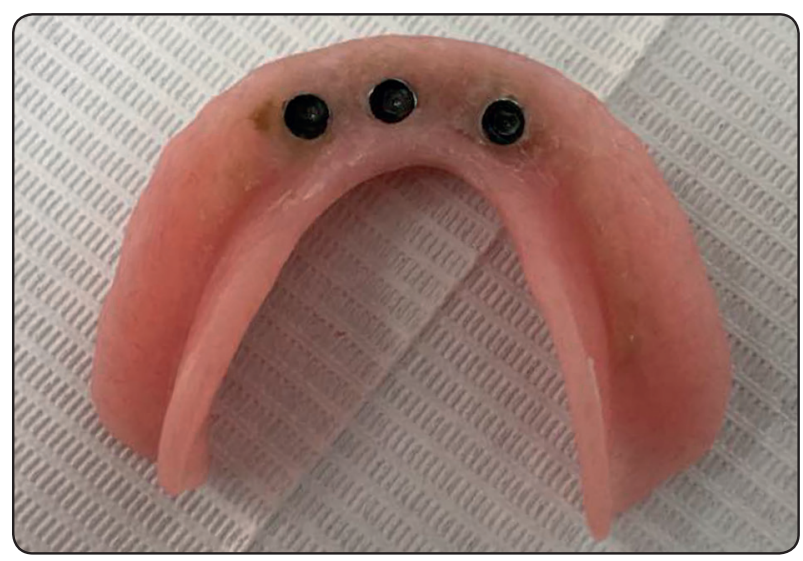

Fig. (3) b: Secondary coping of telescopic attachment

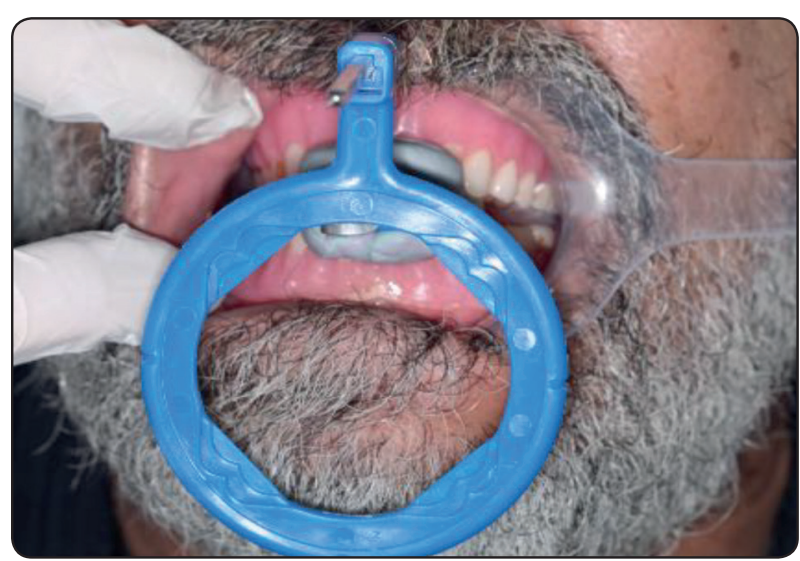

Fig. (4b): Patient biting on bite block

\footnotetext{
* Rinn XCP manufactures C. Ligin, III, USA.

** Ghenesyl addition silicone impression material, Italy.

*** Digora computerized system, Helsinki, Finland.
} 


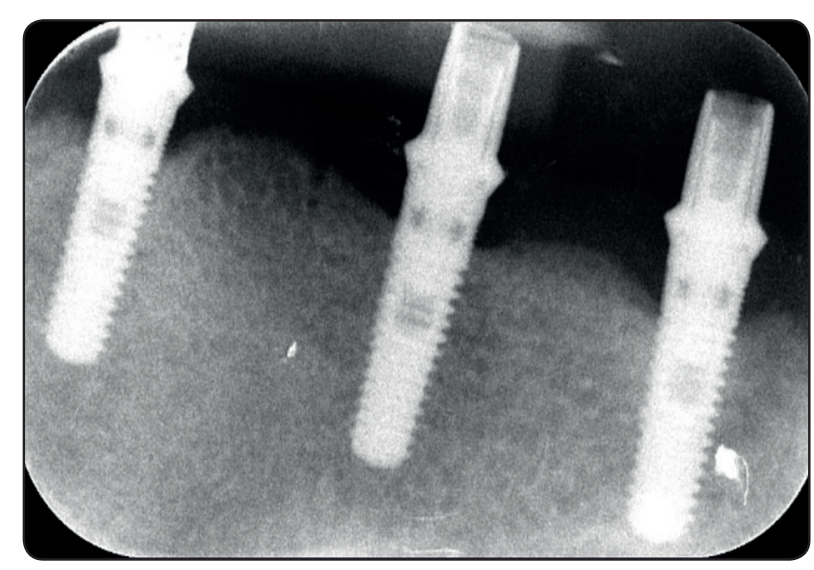

Fig. (5a): Peri-apical X -ray showing three implants

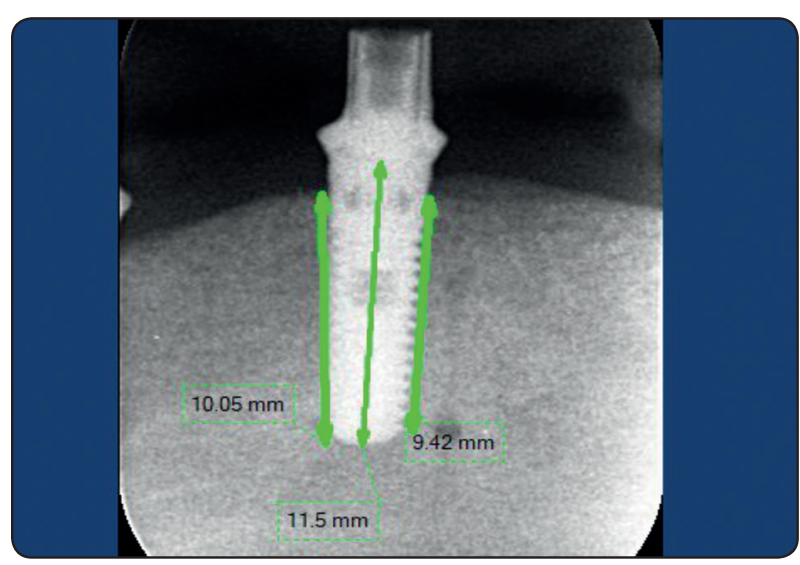

Fig. (5b): Bone height measurements

peri-apical x ray was calibrated by drawing a line from the junction of the implant and abutment to the apical end of the implant, this line was the calibration line corresponding to the implant real length which was $11.5 \mathrm{~mm}$. After the implant was calibrated, a line was drawn on each implant surface; at the mesial and distal surface starting from the first implant thread to bone contact to the apical implant thread to bone contact. The line drawn would correspond to the bone height on each surface (Fig $5 \mathbf{a}, \mathbf{b}$ ). Two blinded operators have carried out the assessment of bone height changes in order to have accurate results. There were no drop outs by the end of the follow up period in all groups.

Data were presented as mean \&standard deviation. Statistical analysis was performed with SPSS 16® (Statistical Package for Scientific Studies), Graph pad prism \& windows excel.

Comparison between different follow up periods was performed by using One Way ANOVA test which insignificant difference between them as $\mathrm{P}>0.05$, followed by Tukey`s Post Hoc test for multiple comparisons which revealed also insignificant difference between each two intervals in all groups as $\mathrm{P}>0.05$

\section{RESULTS}

\section{Comparison of bone height changes between the} three installed implants ( right, midline, and left) in each of the three groups

When comparing the bone height changes between the three installed implants in the three groups of patients in this study; patients with ball attachment, patients with locator attachment, and patients with telescope attachment throughout the different follow up periods it was found that there was no statistically significant differences between the three installed implants for the three groups at base line, and after 3 month follow up. While at 6 month follow up there was a statically significant difference between the right, left and middle implant, and the middle implant showed greater bone height changes than the right and left implants in all of the three groups. Similarly at 12 month follow up period there was also a statistically significant difference between the right, left and middle implant with the middle implant showing more bone height changes in all of the three groups (Table 1, figure 6). 
TABLE (1): Mean, standard deviation \& P value of One-Way ANOVA test of all implants in all follow up periods in three groups.

\begin{tabular}{|c|c|c|c|c|c|c|c|c|c|c|}
\hline \multirow{2}{*}{\multicolumn{2}{|c|}{$\begin{array}{c}\text { Implant } \\
\mathrm{M}\end{array}$}} & \multicolumn{2}{|c|}{ Baseline } & \multicolumn{2}{|c|}{3 months } & \multicolumn{2}{|c|}{6 months } & \multicolumn{2}{|c|}{12 months } & \multirow{2}{*}{$P$ value } \\
\hline & & SD & M & SD & M & SD & M & SD & & \\
\hline \multirow{5}{*}{$\underset{\mathscr{\varpi}}{\bar{\emptyset}}$} & Right & $9.3 \mathrm{a}$ & 1.4 & $9.1 \mathrm{a}$ & 1.37 & $9 \mathrm{a}$ & 0.3 & $8.8 \mathrm{a}$ & 0.26 & 0.79 \\
\hline & Midline & $9 \mathrm{a}$ & 1.35 & $9 \mathrm{a}$ & 1.35 & $8.3 \mathrm{~b}$ & 0.35 & $8.3 \mathrm{~b}$ & 0.24 & 0.27 \\
\hline & Left & $9.5 \mathrm{a}$ & 1.43 & $9.5 \mathrm{a}$ & 1.43 & $9.3 \mathrm{a}$ & 0.31 & $9 \mathrm{a}$ & 0.27 & 0.74 \\
\hline & Overall & 9.27 & 1.39 & $9.2 \mathrm{a}$ & 1.38 & 8.87 & 0.32 & 8.7 & 0.26 & 0.63 \\
\hline & $\mathrm{P}$ value & \multicolumn{2}{|c|}{0.77} & \multicolumn{2}{|c|}{0.74} & \multicolumn{2}{|c|}{$0.0001 *$} & \multicolumn{2}{|c|}{$0.0001 *$} & \\
\hline \multirow{5}{*}{ 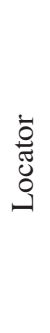 } & Right & 9.88 & 1.48 & 9.7 & 1.46 & $9.55 \mathrm{a}$ & 0.34 & $9.33 \mathrm{a}$ & 0.34 & 0.76 \\
\hline & Midline & 9.2 & 1.38 & 9.05 & 1.36 & $8.87 \mathrm{~b}$ & 0.41 & $8.67 \mathrm{~b}$ & 0.3 & 0.74 \\
\hline & Left & 9.77 & 1.47 & 9.6 & 1.44 & $9.52 \mathrm{a}$ & 0.33 & $9.27 \mathrm{a}$ & 0.31 & 0.81 \\
\hline & overall & 9.62 & 1.44 & 9.45 & 1.42 & 9.31 & 0.36 & 9.09 & 0.32 & 0.77 \\
\hline & $P$ value & \multicolumn{2}{|c|}{0.61} & \multicolumn{2}{|c|}{0.62} & \multicolumn{2}{|c|}{$0.001 *$} & \multicolumn{2}{|c|}{$0.0001 *$} & \\
\hline \multirow{5}{*}{ 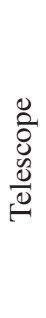 } & Right & 9.7 & 1.46 & 9.65 & 1.45 & $9.6 \mathrm{a}$ & 0.32 & $9.45 \mathrm{a}$ & 0.35 & 0.96 \\
\hline & Midline & 9.1 & 1.37 & 9.1 & 1.37 & $8.8 \mathrm{~b}$ & 0.37 & $8.6 \mathrm{~b}$ & 0.25 & 0.69 \\
\hline & Left & 9.6 & 1.44 & 9.6 & 1.44 & $9.4 \mathrm{a}$ & 0.36 & $9.2 \mathrm{a}$ & 0.31 & 0.84 \\
\hline & overall & 9.47 & 1.42 & 9.45 & 1.42 & 9.27 & 0.35 & 9.08 & 0.3 & 0.98 \\
\hline & $\mathrm{P}$ value & \multicolumn{2}{|c|}{0.67} & \multicolumn{2}{|c|}{0.69} & \multicolumn{2}{|c|}{$0.001 *$} & \multicolumn{2}{|c|}{$0.0001 *$} & \\
\hline
\end{tabular}

\section{M: mean SD: standard deviation. $\quad$ *Significant difference.}

Mean with the same superscript letters were insignificantly different as $P>0.05$.

Mean with different superscript letters were significantly different as $P<0.05$.

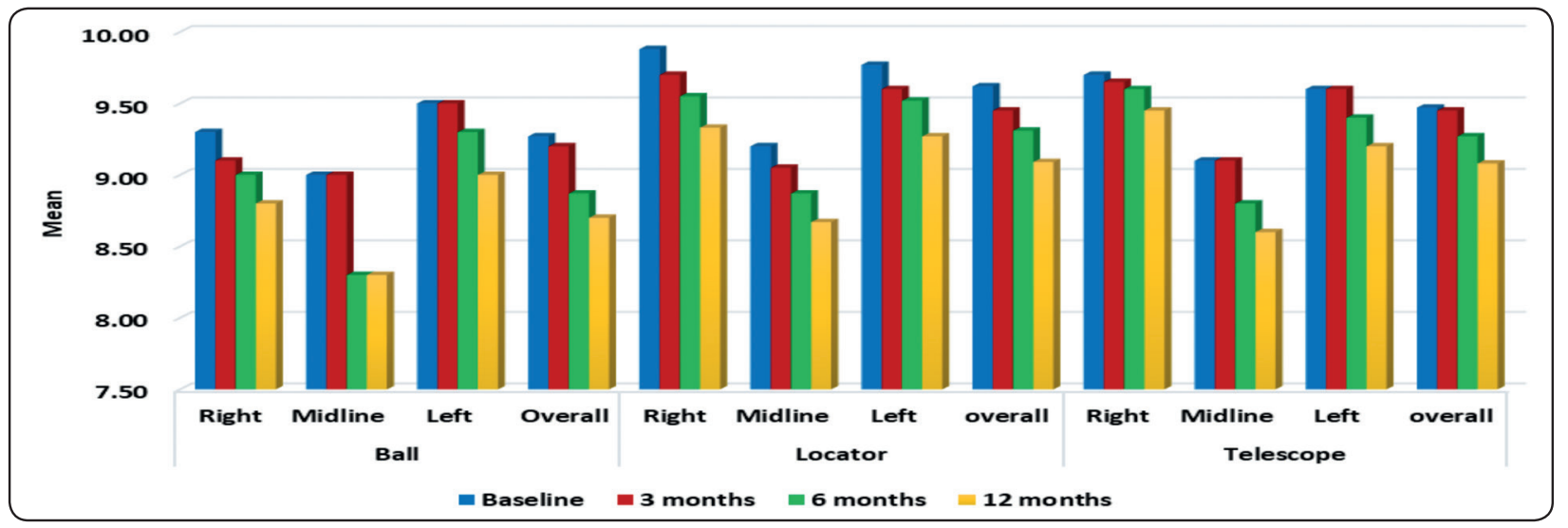

Fig. (6): Bar chart represents comparison between different implants \& different follow up periods in all groups. 
Comparison between the three groups at different follow up intervals

When comparing the bone height changes between the three groups of patients at different follow up intervals, it was found that there was no statistically significant difference between the mean bone height changes for the patients with ball attachment, locator attachment and telescope attachment, at base line and 3 month follow up. But it is clear that greater bone height changes have occurred in the ball attachment group when compared to the locator and telescope attachment, as overall mean bone height changes at base line was for ball, locator and telescope attachment respectively was; $9.27 \pm 1.39$, $9.62 \pm 1.44,9.47 \pm 1.42(\mathrm{p}=0.88)$, and at 3 month follow up bone height changes was; $9.20 \pm 1.38$, $9.45 \pm 1.42,9,45 \pm 1.42(\mathrm{p}=0.91)$ (Table 2, figure 7).

At 6 and 12 month follow up there was a statistically significant difference between the ball, locator and telescope attachment, with the ball attachment having the highest significant bone height changes when compared to the locator and telescope attachment. At 6 month follow up the mean bone height changes for ball, locator and telescope; $8.87 \pm 0.32$, $9.31 \pm 0.36,9.27 \pm 0.35(\mathrm{p}=0.03)$, while at 12 month follow up ; 8.70 $\pm 0.26, \quad 9.09 \pm 0.32, \quad 9.08 \pm 0.3$ ( $\mathrm{p}=0.001$ ) (Table 2, figure 7).There was no significant difference between the locator and telescope attachment at 6 and 12 month follow up intervals.

TABLE (2): Comparison between three groups among all follow up periods

\begin{tabular}{|c|c|c|c|c|c|c|c|c|}
\hline & & \multicolumn{2}{|c|}{ ball } & \multicolumn{2}{|c|}{ Locator } & \multicolumn{2}{|c|}{ Telescope } & \multirow{2}{*}{$\mathrm{P}$ value } \\
\hline & & M & SD & M & SD & M & SD & \\
\hline \multirow{4}{*}{ 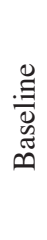 } & Right implant & $9.30 \mathrm{a}$ & 1.40 & $9.88 \mathrm{a}$ & 1.48 & $9.70 \mathrm{a}$ & 1.46 & 0.71 \\
\hline & Midline implant & $9.00 \mathrm{a}$ & 1.35 & $9.20 \mathrm{a}$ & 1.38 & $9.10 \mathrm{a}$ & 1.37 & 0.95 \\
\hline & Left implant & $9.50 \mathrm{a}$ & 1.43 & $9.77 \mathrm{a}$ & 1.47 & $9.60 \mathrm{a}$ & 1.44 & 0.93 \\
\hline & Overall & $9.27 \mathrm{a}$ & 1.39 & $9.62 \mathrm{a}$ & 1.44 & $9.47 \mathrm{a}$ & 1.42 & 0.88 \\
\hline \multirow{4}{*}{ 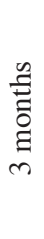 } & Right implant & $9.10 \mathrm{a}$ & 1.37 & $9.70 \mathrm{a}$ & 1.46 & $9.65 \mathrm{a}$ & 1.45 & 0.62 \\
\hline & Midline implant & $9.00 \mathrm{a}$ & 1.35 & $9.05 \mathrm{a}$ & 1.36 & $9.10 \mathrm{a}$ & 1.37 & 0.98 \\
\hline & Left implant & $9.50 \mathrm{a}$ & 1.43 & $9.60 \mathrm{a}$ & 1.44 & $9.60 \mathrm{a}$ & 1.44 & 0.98 \\
\hline & Overall & $9.20 \mathrm{a}$ & 1.38 & $9.45 \mathrm{a}$ & 1.42 & $9.45 \mathrm{a}$ & 1.42 & 0.91 \\
\hline \multirow{4}{*}{ 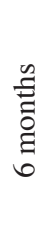 } & Right implant & $9.00 \mathrm{a}$ & 0.30 & $9.55 \mathrm{~b}$ & 0.34 & $9.60 \mathrm{~b}$ & 0.32 & $0.001 *$ \\
\hline & Midline implant & $8.30 \mathrm{a}$ & 0.35 & $8.87 \mathrm{~b}$ & 0.41 & $8.80 \mathrm{~b}$ & 0.37 & $0.01 *$ \\
\hline & Left implant & $9.30 \mathrm{a}$ & 0.31 & $9.52 \mathrm{a}$ & 0.33 & $9.40 \mathrm{a}$ & 0.36 & 0.41 \\
\hline & Overall & $8.87 \mathrm{a}$ & 0.32 & $9.31 \mathrm{~b}$ & 0.36 & $9.27 \mathrm{~b}$ & 0.35 & $0.03 *$ \\
\hline \multirow{4}{*}{ 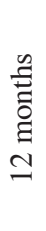 } & Right implant & $8.80 \mathrm{a}$ & 0.26 & $9.33 \mathrm{~b}$ & 0.34 & $9.45 \mathrm{~b}$ & 0.35 & $0.001 *$ \\
\hline & Midline implant & $8.30 \mathrm{a}$ & 0.24 & $8.67 \mathrm{~b}$ & 0.30 & $8.60 \mathrm{~b}$ & 0.25 & $0.02 *$ \\
\hline & Left implant & $9.00 \mathrm{a}$ & 0.27 & $9.27 \mathrm{a}$ & 0.31 & $9.20 \mathrm{a}$ & 0.31 & 0.19 \\
\hline & Overall & $8.70 \mathrm{a}$ & 0.26 & $9.09 \mathrm{~b}$ & 0.32 & $9.08 \mathrm{~b}$ & 0.30 & $0.001 *$ \\
\hline
\end{tabular}

M: mean SD: standard deviation. $\quad$ *Significant difference.

Mean with the same superscript letters were insignificantly different as $P>0.05$.

Mean with different superscript letters were significantly different as $P<0.05$. 


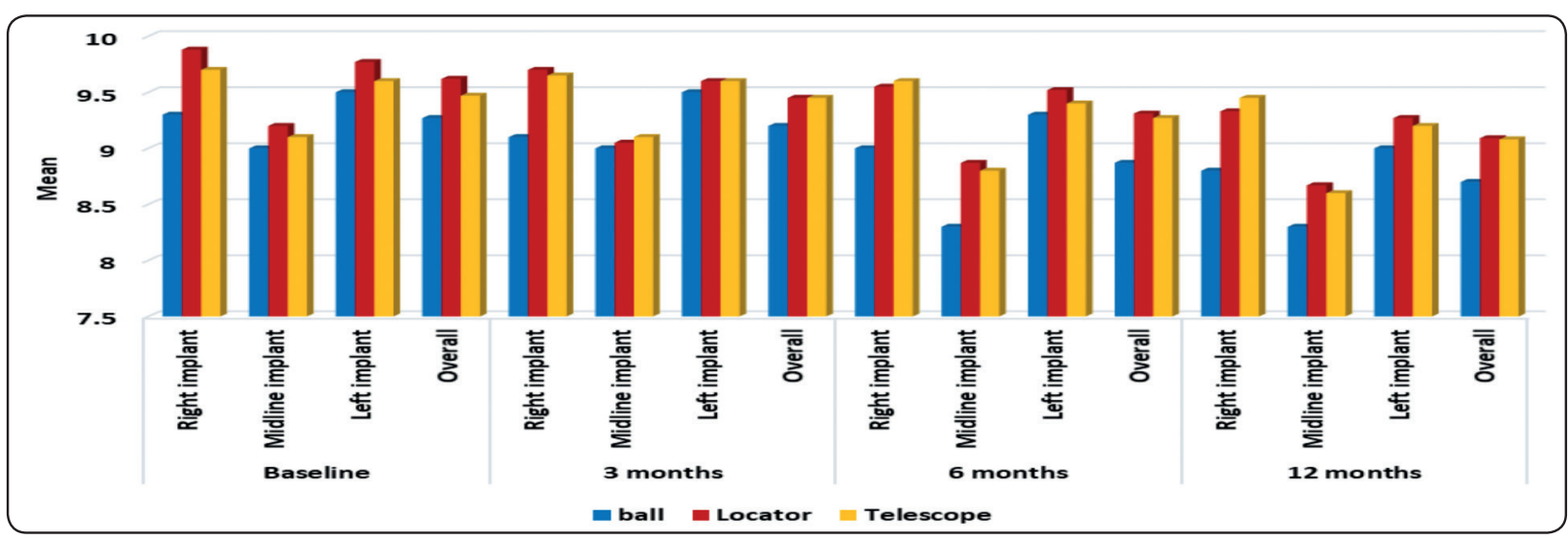

Fig. (7): Bar chart represents comparison between different groups in all follow up periods regarding all implants.

\section{DISCUSSION}

Proper prosthetic rehabilitation can reduce the bone resorption that arises after the loss of teeth ${ }^{34,35}$. After successful osseointegration of dental implant, the concept of implant over denture has been accepted worldwide as a consistent treatment protocol for the rehabilitation of completely edentulous patients ${ }^{37-41}$. The implant over denture have become the standard of care because of the superior stability derived from the mechanical attachment retaining the restoration, limited lateral movements that subsequently minimize soft tissue trauma. ${ }^{39,42,43}$

Although, two intermorainal implants are considered as the least requirement and as the regular treatment program for implant prosthetic rehabilitation of the edentulous mandible, removable prosthetic solutions would depend on multiple implants.$^{44}$ Three and four implants were found to be more secure than two implants, it was concluded that three or four implants would be recommended when increased retention is required. ${ }^{45}$ Furthermore Uludag et al. ${ }^{46}$ reported that retentive values of the three-implant-assisted overdenture model are considerably higher than the two-implant overdenture model. Oda et al. ${ }^{47}$ reported that three implants were more advantageous than the use of two-implants as it reduces denture base rotation during incising. Moreover, Selda et al.$^{48}$ concluded that increasing of implant number would cause lower stresses in peri-implant bone in both splinted and un-splinted attachments that are provoked by a bite force applied to the mandible. That was the reason why we have installed three implants in the present trial.

Placement of more than two implants in the edentulous mandible would produce an angular relation rather than a straight-line relationship between the implants, as the most anterior implant would avoid intrusion of the anterior part of the denture in a tissue ward movement ${ }^{49}$ This would explain the results of our present study, the implant installed in the mid line was more anterior to the two distal implants resulting in tripod distribution, this implant in the mid line have recorded the greatest decrease in mean bone height changes after 6 and 12 month follow up, as it have shared a greater part of the forces than the other two distal implants, due to the intrusive forces that was falling on this implant to prevent the tissue ward movement of the anterior part of the denture

One of the long-term clinical evaluation of the implants used to support an overdenture is observing of the marginal bone level around the 
implants. Changes in marginal bone levels that are outside the physiologic limits would result in loss of bone height around the anchoring implant. Bone loss of around $1.5 \mathrm{~mm}$ after the first year of loading with an extra $0.2 \mathrm{~mm}$ amount of bone loss per year is considered to be within the physiologic limits. ${ }^{26,50,51}$ The assessment of changes in bone height around the implants can be done by comparing standardized peri-apical $\mathrm{x}$-rays at different intervals. In the present study standardized peri-apical $x$-rays were being used to determine the changes in bone height changes.

A key factor for success or failure of dental implants is reliant on the way in which stresses are transferred to peri-implant bone. ${ }^{52}$ When stress patterns produced in splinted and non-splinted attachment types were compared, stresses were discovered to be less in non-splinted model. This can be attributed to the fact that, in non-splinted attachment model only vertical compressive forces was applied to the underlying implants. On the other hand, in splinted ones, the joined vertical compressive force along with the bending moment might have produced high stress. Similarly, because of the cantilever effect of splinted bar, the deflection was of greater value causing high stresses at the level of the contact zone of the abutment, implant and screw. ${ }^{53}$

In the present trial the ball and locator attachment are considered as unsplinted attachment, while for the telescope attachment it exerted a secondary splinting effect. Results of the present study showed that the ball attachment has recorded the greatest bone height changes when compared to the locator and telescope attachment. This comes in agreement with Kutzman $2009^{54}$, and Evitmovska E et al $2009{ }^{55}$ who concluded that the locator attachment presented less Von Mises stress values than the ball attachment with vertical and oblique loading conditions in implant-abutment complex, supporting alveolar bone and the resilient caps.
This is probably related to the low-profile design of the locator attachment and to the rotational pivoting character of its abutment that is sponsored to lower the rotational center and to possibly reduce the lateral forces. The resilience of the locator attachment could be a significant factor to allow anteroposterior movement, laterally and intrusive therefore, decreasing the resultant stresses on the implants and supporting peri-implant bone. ${ }^{54,55}$ Though, both attachment caps shared comparable crushing effect dissipating the induced stresses, it appeared that the greater thickness of the acrylic overdenture overlying the locator's cap as a result of the low-profile design of the locator attachment worked as a mechanical absorber taking highest of the applied load therefore reducing the induced stresses radiating to the locator's cap. ${ }^{56}$

For the telescopic attachment the circumferential relation among the outer and inner copings that have resulted in improved force distribution with axial transfer of occlusal forces resulting in reduced torque to the underlying abutments. Telescopic retainers apart from providing improved retentive and stabilizing properties with a splinting action. ${ }^{10,75}$ This would explain why there was no significant differences between the bone height changes between the locator and the telescopic retainer.

\section{CONCLUSION}

It can be concluded from the present trial that the ball, locator, and telescopic attachment have proved to be a reliable treatment option for a three implant retained mandibular overdenture. After 6 and 12 month follow up the implant installed in the mid line showed the greatest significant bone height changes when compared to the right and left implants, in addition to that the ball attachment have experienced the greatest significant bone height changes when compared to the locator and telescopic attachment after 12 month follow up period. 


\section{REFERENCES}

1. Awad MA, Rashid F, Feine JS; Overdenture Effectiveness Study Team Consortium. The effect of mandibular 2-implant overdentures on oral health- related quality of life: an international multicentre study. Clin Oral Implants Res. 2014;25:46-51.

2. Awad MA, Lund JP, Dufresne E, Feine JS. Comparing the efficacy of mandibular implant-retained overdentures and conventional dentures among middle-aged edentulous patients: satisfaction and functional assess- ment. Int $\mathbf{J}$ Prosthodont 2003;16:117-22.

3. Jivraj S, Chee W, Corrado P. Treatment planning of the edentulous maxilla. Br Dent J .2006;201:261-79.

4. Martin-Ares M, Barona-Dorado C, Guisado-Moya B, Martinez- Rodriguez N, Cortes-Breton-Brinkmann J, Martinez-Gonzalez JM. Pros- thetic hygiene and functional efficacy in completely edentulous patients: satisfaction and quality of life during a 5-year follow-up. Clin Oral Implants Res .2016;27:1500-5.

5. Kim, H. Y., Lee, J. Y., Shin, S. W., \& Bryant, S. R. (2012). Attachment systems for mandibular implant overdentures: a systematic review. J Adv Prosthodont. 2012; 4, 197-203.

6. Chung KH, Chung CY, Cagna DR, Cronin RJ Jr. Retention cha- racteristics of attachment systems for implant overdentures. J Pros- thodont. 2004;13:221-6.

7. Heckmann SM, Winter W., Meyer M., Weber HP., Wichmann MG. Overdenture attachment selection and loading of implant and denture bearing area. Part 1: in vivo verification of stereolithographic model. Clin Oral Implants Res 2001; 12:617-623.

8. Mericske-Stern RD, Taylor TD, Besler U. Management of the edentulous patient. Clin Oral Implants Res 2000; 11:108-25

9. Langer A. Telescope retainer for removable partial dentures. J Prosthet Dent.1981a; 45:37

10. Langer A. Tooth supported telescopic restorations. J Prosthet Dent.1981 b; 44:515.

11. Frisch E, Ziebolz D, Ratka KP and Rinke S .Double Crown Retained Maxillary Overdentures: 5 Year Follow Up." Clin Implant. Dent Relat Res 2005; 17: 22-31

12. Babbush, C.A.; Tallarico, M. Twelve-year clinical and radiological results of maxillary and mandibular implantretained bar overdentures carried out on oxidized (TiUnite) replace select implants: A clinical case. J Oral Implantol. 2013, 39, 737-742.

13. Scrascia, R.; Martinolli, M.; Venezia, P.; Casucci, A.; Ortensi, L.; Tallarico, M. Feasibility of Low Profile Attachments to Improve Quality of Life on Patients with ImplantRetained Mandibular Overdenture: 1-Year Preliminary Results of a Multicenter Prospective Case Series Study. J. Oral Health Dental Manag. 2018, 17, 5.

14. Preiskel, H. Overdentures Made Easy: A Guide to Implant and Root Supported Prostheses, 1st ed.; Quintessence Publishing Co. Inc.: Chicago, IL, USA, 1996.

15. Alsabeeha, N.H.; Payne, A.G.; Swain, M.V. Attachment systems for mandibular two-implant overdentures: A review of in vitro investigations on retention and wear features. Int. J. Prosthodont. 2009, 22, 429-440.

16. Ortensi L, Martinolli M, Borromeo C, Ceruso FM, Gargari M, Xhanari E, Tallarico M. Effectiveness of ball attachment systems in implant retained-and supported-overdentures: A three-to five-year retrospective examination. Dentistry journal. $2019 ; 7: 84$.

17. Krennmair G, Seemann R, Fazekas A, Ewers R, Piehslinger E. Patient preference and satisfaction with implantsupported mandibular overdentures retained with ball or locator attachments: a crossover clinical trial. Int J Oral Maxillofac Implants. $2012 ; 27$.

18. Trakas T, Michalakis K, Kang K, Hirayama H. Attachment systems for implant retained overdentures: a literature review. Implant Dent . 2006 ; 15:24-34.

19. Evtimovska E, Masri R, Driscoll CF, Romberg E. The change in retentive values of locator attachments and hader clips over time. Journal of Prosthodontics: Implant, Esthetic and Reconstructive Dentistry. 2009;18:479-83.

20. Payne, A.G.; Alsabeeha, N.H.; Atieh, M.A.; Esposito, M.; Ma, S.; Anas El-Wegoud, M. Interventions for replacing missing teeth: Attachment systems for implant overdentures in edentulous jaws. Cochrane Database Syst. Rev. 2018,10 .

21. ELsyad MA, Errabti HM, Mustafa AZ. Mandibular denture base deformation with Locator and ball attachments of implant-retained overdentures. Journal of Prosthodontics. 2016;25:656-64.

22. Sadig W. A comparitive in vitro study on the retention and stability of implant-supported over dentures. Quintessence Int. 2009; 40: 313-319. 
23. Feine JS, Carlsson GE, Awad MA, et al. The McGill Consensus Statement on Overdentures. Montreal, Quebec, Canada,. Int J Prosthodont. 2002;15:413-414.

24. British Society for the Study of Prosthetic Dentistry. The York consensus statement on implant-supported overdentures. Eur J Prosthodont Restorative Dent 2009; 17:164-165.

25. Alberktsson T., Zarb G., Worthington P., Eriksson AR. The long term efficacy of currently used dental implants: A review and proposed criteria of success.Int J Oral Maxillofac Implants 1986;1:11-25.

26. Karoussis IK, Bragger U, Salvi GE, Burgin W, Lang NP. Effect of implant design on survival and success rates of titanium oral implants: A 10 year prospective cohort study of the ITI Dental implant system. Clin Oral Implants Res. 2004; $15: 8-17$.

27. Renvert S., Roos-Jansaker AM, Lindhal C, Renvert H., Rutger Persson G. Infection at titanium implants with or without a clinical diagnosis of

28. Truhlar R8. S, Casino AJ, Cancro JJ. Treatment planning in the elderly implant patients. Dental Clin North Am $.1997 ; 41: 847-61$

29. Jung Y13. C, Han CH, Lee KW. A 1-year radiographic evaluation of marginal bone around dental implants. Int $\mathrm{J}$ Oral Maxillofac Implants 1996;11:811-8.

30. Kitamura 14. E, Stegaroiu R, Nomura S, Miyakawa O. Influence of marginal bone resorption on stress around an implant - a three-dimensional finite element analysis. J Oral Rehabil .2005;32:279-86.

31. Meijer H15. J, Raghoebar GM, Van't Hof MA, Visser A. A controlled clinical trial of implant-retained mandibular overdentures: 10 years results of clinical aspects and aftercare of IMZ implants and Branemark implants. Clin Oral Implants Res .2000;11:441-7.

32. Meijer HJ, Kuiper JH, Starmans FJ, Bosman F. Stress distribution around dental implants: Influence of superstructure, length of implants, and height of mandible. J Prosthet Dent .1992;68:96-102

33. Menicucci G, Lorenzetti M, Pera P, Preti G. Mandibular implant retained overdenture: Finite element analysis of two anchorage systems. Int J Oral Maxillofac Implants .1998;13:369-376.

34. Abdel Nabi N. The influence of inter-implant distance on bone height changes for a three implant retained man- dibular telescopic overdenture. Egyptian Dental Journal. $2017 ; 63: 2821-33$

35. Burns DR. The mandibular complete overdenture. Dent Clin North Am. 2004;48:603-623.

36. Samra RK, Bhide SV, Goyal C, Kaur T. Tooth supported overdenture. A concept overshadowed but not yet forgotten. J Oral Res Rev. 2015;7:16-21.

37. Burns DR. Mandibular implant overdenture treatment: consensus and controversy. J Prosthodont. 2000;9:37-46.

38. von Wowern N, Gotfredsen K. Implant-supported overdentures, a prevention of bone loss in edentulous mandibles? A 5-year follow-up study. Clin Oral Implants Res. 2001;12:19-25

39. Sadowsky SJ. Mandibular implant-retained overdentures: a literature review. J Prosthet Dent. 2001;86:468-473.

40. Kordatzis K, Wright PS, Meijer HJ. Posterior mandibular residual ridge resorption in patients with conventional dentures and implant overdentures. Int J Oral Maxillofac Implants. 2003;18:447-452

41. Roldan AL, Santolaya AD, Bertomeu IG, Castillo EG, Otaolaurruchi ES. Bone resorption processes in patients wearing overdentures. A 6-years retrospective study. J Clin Exp Dent. 2009;1:24-30

42. Trakas T, Michalakis K, Kang K, Hirayama H. Attachment systems for implant retained overdentures: a literature review. Implant Dent. 2006;15:24-34.

43. Kim HY, Lee YJ, Shin SW, Bryant SR. Attachment systems for mandibular implant overdentures: a systematic review. J Adv Prosthodont. 2012;4:197-203.

44. Krennmair G, Krainhöfner M, Piehslinger E. The influence of bar design (round versus milled bar) on prosthodontic maintenance of mandibular overdentures supported by 4 implants: a 5-year prospective study. Int J Prosthodont. 2008;21.

45. Bilhan SA, Baykasoglu C, Bilhan H, Kutay O, Mugan A. Effect of attachment types and number of implants supporting mandibular overdentures on stress distribution: a computed tomography-based 3D finite element analysis. Journal of biomechanics. $2015 ; 48: 130-7$.

46. Uludag B, Polat S. Retention characteristics of different attachment systems of mandibular overdentures retained by two or three implants. Int J Oral Maxillofac Implants. 2012;27:1509-1513. 
47. Oda K, Kanazawa M, Takeshita S, et al. Influence of implant number on the movement of mandibular implant overdentures. J Prosthet Dent. 2017;117:380-385.

48. Selda A, Cengiz B, Hakan B, et al. The effect of attachment types and number of implants supporting mandibular overdentures on stress distribution: A computed tomography-based 3D finite element analysis. J Biomech. 2015;48:130-137.

49. Ben-Ur Z, Gorfil C., Shifman A. Anterior implant-supported overdentures. Quintessence Int .1997; 27:603

50. Alberktsson T., Zarb G., Worthington P., Eriksson AR. The long term efficacy of currently used dental implants: A review and proposed criteria of success.Int J Oral Maxillofac Implants 1986;1:11-25.

51. Renvert S., Roos-Jansaker AM, Lindhal C, Renvert H., Rutger Persson G. Infection at titanium implants with or without a clinical diagnosis of inflammation. Clin Oral Implants Res. 2007;18:509-516.

52. Eltaftazani I, Moubarak A, El-Anwar M. Locator attach- ment versus ball attachment: 3-dimensional finite element study. Egypt Dent J. 2011;57:73-85

53. Abbasi MR, Vinnakota DN, Vijaya Sankar V, Kamatham R. Comparison of stress induced in mandible around an implant-supported overdenture with locator attachment and telescopic crowns-a finite element analysis. Medicine and Pharmacy Reports. 2020 ;93:181.

54. Kurtzman GM. The locator attachment: Free standing versus bar overdentures. Dent Labor Int plus. 2009; 1:20-23.

55. Evtimovska E, Masri R, Driscoll CF, Romberg E. The change in retentive values of locator attachments and hader clips over time. J Prosthodont. 2009; 18:479-483.

56. El-Anwar MI, El-Taftazany EA, Hamed HA, Abd ElHay MA. Influence of number of implants and attachment type on stress distribution in mandibular implant-retained overdentures: Finite element analysis. Open access Macedonian journal of medical sciences. 2017 15;5:244.

57. Langer A. Telescope retainer for removable partial dentures. J Prosthet Dent.1981a; 45:37. 